\title{
Respiratory impedance response to continuous negative airway pressure in awake controls and OSAS
}

\author{
A.M. Lorino*, F. Lofaso*, E. Dahan*, A. Harf*, H. Lorino*
}

Respiratory impedance response to continuous negative airway pressure in awake controls and OSAS. A.M. Lorino, F. Lofaso, E. Dahan, A. Harf, H. Lorino. (C)ERS Journals Ltd 2001.

ABSTRACT: The aim of the study was to determine whether the response of respiratory impedance $\left(Z_{\mathrm{rs}}\right)$ to decreasing levels of continuous negative airway pressure (CNAP) during wakefulness, differs in controls and subjects with obstructive sleep apnoea syndrome (OSAS).

$Z_{\text {rs }}$ was measured by the forced oscillation technique $(4-32 \mathrm{~Hz})$ in 15 controls and 21 patients with OSAS (apnoea/hypopnoea index $>20$ per sleep hour) with normal lung function, in the basal state and with application of decreasing CNAP of $-5,-10$, and $-15 \mathrm{hPa}$. Respiratory resistance was extrapolated to $0 \mathrm{~Hz}(R 0)$ and estimated at $16 \mathrm{~Hz}$ $(R 16)$ by linear regression analysis of respiratory resistive impedance versus frequency. Respiratory elastance $\left(E_{\mathrm{rs}}\right)$ and inertance $(\mathrm{Irs})$ were estimated by multilinear regression analysis of respiratory reactance versus frequency, and resonance frequency $(\mathrm{RF})$ was determined as $\mathrm{RF}=(1 / 2 \pi)(E \mathrm{rs} / I \mathrm{rs})^{0.5}$.

In both groups, $R 0, R 16, E$ rs and $R F$ significantly increased as the CNAP level decreased $\left(\mathrm{p}<\mathbf{0 . 0 0 0 1}\right.$ for all). $\boldsymbol{R} 0, E_{\mathrm{rs}}$, and $\mathrm{RF}$ increased significantly more in OSAS than in controls $(p<0.01,0.001$, and 0.0001 , respectively), independently of the severity of obesity. Receiver operator characteristic curves showed that the parameter which best detected OSAS was RF, with a sensitivity of $81 \%$ and $93 \%$ specificity for the $13.6 \mathrm{~Hz}$ cut-off point.

The results of the present study suggest that the response of respiratory impedance to decreasing continuous negative airway pressure levels, might allow detection of obstructive sleep apnoea syndrome in subjects with normal lung function.

Eur Respir J 2001; 17: 71-78.
*INSERM U 492 et Service de Physiologie, Hôpital Henri Mondor, AP-HP et Université Paris XII, Créteil, France. ${ }^{\#}$ Service de Physiologie, Hôpital Raymond Poincaré, AP-HP, Garches, France.

Correspondence: A.M. Lorino

Service de Physiologie - Explorations Fonctionnelles

Hôpital Henri Mondor

94010 Créteil

France

Fax: 33149812698

Keywords: Continuous negative airway pressure

forced oscillations

obstructive sleep apnoea syndrome respiratory elastance

respiratory resistive impedance

Received: March 142000

Accepted after revision September 16 2000
Obstructive sleep apnoea/hypopnoea syndrome (OSAS) is characterized by the occurrence of repetitive upper airway (UA) narrowing and/or closure during sleep. Obstructive respiratory events are generally explained by the inefficiency of the dilating muscles in counterbalancing the tendency of the pharyngeal airway to collapse, due to the inspiratory decrease in UA transmural pressure [1]. The main factors predisposing subjects to OSAS appear to be: 1) a reduction of UA calibre [2]; 2) an increase in UA resistance, as well as in pulmonary and respiratory resistances [3-5]; 3) an increase in UA compliance [4, 6, 7]; and 4) dysfunction of the UA dilating muscles [8].

The application of continuous negative airway pressure (CNAP) at the airway opening generates a subatmospheric intraluminal UA pressure that simulates the conditions promoting the occurrence of obstructive respiratory events. The effect of CNAP on pharyngeal cross-sectional area and resistance have been widely investigated in control and OSAS subjects [4, 8-11], but, to the authors' knowledge, CNAPinduced changes in the respiratory mechanical parameters remain poorly documented [12]. The aim of the present study was, therefore, to investigate whether the response of respiratory mechanics to decreasing CNAP levels differs between control and OSAS subjects, and might provide a predictive index of OSAS. To this end, the forced oscillation technique (FOT) was used, which allows easy measurement of respiratory impedance (Zrs) during CNAP application.

\section{Materials and methods}

\section{Subjects}

The authors studied 36 subjects in two groups. The control group consisted of 15 asymptomatic healthy subjects (9 males), aged 31-57 yrs (mean \pm sD $47 \pm 12$ $\mathrm{yrs}$ ), with a body mass index (BMI) $<29 \mathrm{~kg} \cdot \mathrm{m}^{-2}$, (mean $24.1 \pm 2.9 \mathrm{~kg} \cdot \mathrm{m}^{-2}$ ), and no upper or lower respiratory complaints. None of the subjects were habitual snorers, and none complained of the diurnal or nocturnal symptoms seen with sleep apnoea syndrome. The OSAS group consisted of 21 patients with moderateto-severe OSAS (17 males) aged $34-78$ yrs (mean $54.6 \pm 10.9 \mathrm{yrs})$. This group was initially divided into two subgroups according to the subjects' BMI. OSAS 
$(\mathrm{n}=11)$ comprised patients with $\mathrm{BMI}<29 \mathrm{~kg} \cdot \mathrm{m}^{-2}$ (mean $\left.25.0 \pm 2.3 \mathrm{~kg} \cdot \mathrm{m}^{-2}\right)$, and $\mathrm{OSAS}_{2}(\mathrm{n}=10)$, those with BMI $\geqslant 29 \mathrm{~kg} \cdot \mathrm{m}^{-2}\left(\right.$ mean $\left.=32.7 \pm 3.9 \mathrm{~kg} \cdot \mathrm{m}^{-2}\right)$. All patients had normal lung volumes and forced expiratory flow rates $(\geqslant 80 \%$ of predicted values), and no history of cardiopulmonary disease. Their apnoea/hypopnoea index, established previously on the basis of overnight polysomnography, ranged from 20-87 per sleep hour (mean $44 \pm 25$ per sleep hour). The experimental protocol had the prior approval of the authors' hospital Ethics Committee, and all subjects gave informed consent.

\section{Respiratory resistance measurement}

$Z$ rs was measured at the mouth by FOT. The pseudorandom forced flow used in this study was composed of 29 harmonics $(4-32 \mathrm{~Hz})$, with enhanced amplitudes at the lower frequencies, to limit the influence of spontaneous breathing. The forced signal, generated by a digital-to-analogue converter, excited, through a power amplifier, a 50-W loudspeaker (Audax HM 130 XO, Château du Loir, France) enclosed in a 25-litre rigid chamber and placed in parallel with the CNAP device, as previously described [13]. Mouth flow was measured with a screen pneumotachograph (resistance $=0.35$ $\mathrm{hPa} \cdot \mathrm{L}^{-1} \cdot \mathrm{s}$; Jaeger, Wurzburg, Germany) connected to a differential pressure transducer $( \pm 70 \mathrm{hPa}$; Sensym SCX 01D, Sunnyvale, CA, USA), and mouth pressure by a similar pressure transducer referenced to the atmosphere. The pneumotachograph and the tubing were flushed by a constant bias flow $\left(0.5 \mathrm{~L} \cdot \mathrm{s}^{-1}\right)$. Pressure and flow data were collected over $16 \mathrm{~s}$ periods and high-pass filtered (3rd order, cut-off frequency $3.5 \mathrm{~Hz}$ ) to eliminate the breathing noise. A fast Fourier transform algorithm was applied to adjacent $4 \mathrm{~s}$ periods. Impedance data were calculated from the auto- and cross-spectra of pressure and flow, averaged over 3-4 manoeuvres, and retained for analysis when coherence was $\geqslant 0.9$ [14]. Respiratory resistance $(R \mathrm{rs})$ was submitted to linear regression analysis versus frequency over the 4-16 and $17-32 \mathrm{~Hz}$ frequency ranges. Rrs extrapolated to $0 \mathrm{~Hz}(R 0)$ was derived from the first linear regression analysis, and $R$ rs estimated at $16 \mathrm{~Hz}$ $(R 16)$, from the second one [15]. The frequency dependence of $R \mathrm{rs}$ was assessed by the difference $\Delta R \mathrm{rs}=R 0$ $R 16$. Respiratory elastance (Ers) and inertance (Irs) were estimated by multilinear regression analysis of respiratory reactance versus frequency. Resonance frequency (RF) was determined as the frequency corresponding to the zero value of respiratory reactance, i.e. as $\mathrm{RF}=(1 /$ $2 \pi)\left(E_{\mathrm{rs}} / I_{\mathrm{rs}}\right)^{0.5}$.

\section{Experimental protocol}

Each subject was studied in the sitting position under four successive conditions: in the basal state $\left(\mathrm{CNAP}_{0}\right)$, and with decreasing levels of CNAP of $-5,-10$, and -15 hPa $\left(\mathrm{CNAP}_{-5}, \mathrm{CNAP}_{-10}\right.$, and $\mathrm{CNAP}_{-15}$, respectively) applied at the mouth. CNAP was generated by an adjustable vacuum source, set at the negative pressure required before the subject was connected to the breathing circuit, and continuously monitored with a manometer. The subject, wearing a nose clip and firmly supporting his cheeks with his hands, was then connected to the CNAP device, and asked to breathe quietly and not to fight the applied pressure. After a $30 \mathrm{~s}$ period of adaptation to CNAP, forced oscillation was applied for $16 \mathrm{~s}$, and the subject was disconnected from the CNAP device for $2 \mathrm{~min}$. This sequence was repeated 3-4 times at each CNAP level, and a 5 min period was allowed to pass after the last release from one CNAP level before the first application of the next CNAP level.

\section{Data analysis}

Values are mean \pm SEM, except when otherwise indicated. Statistical analysis of data was performed using linear regression analysis, analysis of variance, paired t-tests, and unpaired t-tests. A value of $\mathrm{p}<0.05$ was considered significant.

The sensitivity and specificity of possible cut-off points for $R 0, E \mathrm{rs}$, and $\mathrm{RF}$, to discriminate between control subjects and OSAS patients, were studied using the receiver operator characteristic (ROC) curve [16]. The ROC curve allowed the visualization of the true positive rate (sensitivity) as a function of the false positive rate (1-specificity) for the different values of the respiratory parameters, and the determination of the cut-off point corresponding to the best compromise between sensitivity and specificity, defined as the closest point of the curve to the upper left hand corner.

\section{Results}

There was no significant difference in age between controls and patients with OSAS. No significant difference was observed either for BMI between controls and $\mathrm{OSAS}_{1}$, but BMI was significantly higher in $\mathrm{OSAS}_{2}$ than in controls and $\mathrm{OSAS}_{1}(\mathrm{p}<0.0001$ for both).

With $\mathrm{CNAP}_{0}, R 0$ and $R 16$ were significantly higher in groups $\mathrm{OSAS}_{1}$ and $\mathrm{OSAS}_{2}$ than in controls, but the small difference between $\mathrm{OSAS}_{1}$ and $\mathrm{OSAS}_{2}$ was not significant (fig. 1). Within each group, no significant difference was observed between $R 0$ and $R 16$. Ers and RF were slightly but significantly higher in group $\mathrm{OSAS}_{2}$ than in controls and OSAS 1 (fig. 2), and Irs was slightly but significantly lower in $\mathrm{OSAS}_{2}$ than in controls $\left(0.012 \pm 0.001\right.$ versus $\left.0.014 \pm 0.001 \mathrm{hPa} \cdot \mathrm{s}^{2} \cdot \mathrm{L}^{-1}\right)$.

A typical response of respiratory impedance to decreasing CNAP levels, obtained in a representative OSAS subject, is shown in figure 3. Interestingly, the differences observed for the respiratory mechanical parameters at $\mathrm{CNAP}_{0}$ between $\mathrm{OSAS}_{1}$ and $\mathrm{OSAS}_{2}$, disappeared as the CNAP level decreased, and no significant differences were observed for the mechanical parameter responses to decreasing CNAP levels between $\mathrm{OSAS}_{1}$ and $\mathrm{OSAS}_{2}$ (figs. 1 and 2). Therefore, in what follows, the results will be presented for controls and OSAS, without making a distinction between $\mathrm{OSAS}_{1}$ and $\mathrm{OSAS}_{2}$.

In both control and patient groups, $R 0, R 16$, and the difference $\Delta R \mathrm{rs}=R 0-R 16$ increased significantly as the CNAP level decreased ( $p<0.0001$ for all, fig. 4). The CNAP-induced increases in $R 0$ and $\Delta R$ rs were significantly greater in patients than in controls $(\mathrm{p}<0.01$ 

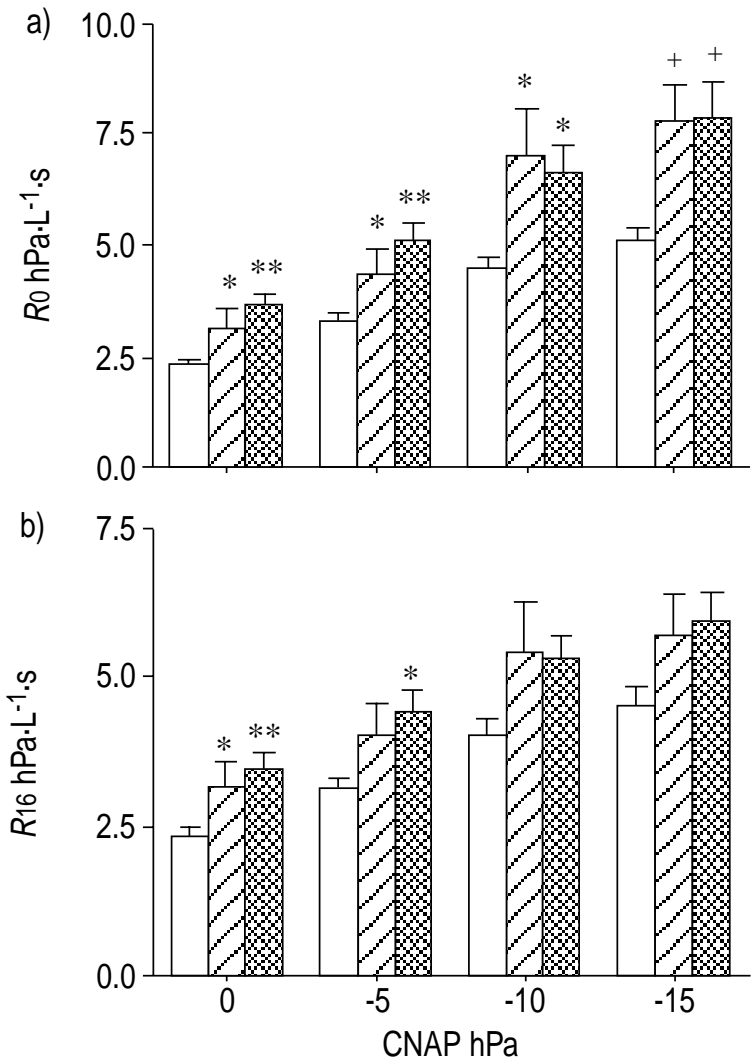

Fig. 1. - Respiratory resistive impedance a) extrapolated to 0 $\mathrm{Hz}(R 0)$ and b) estimated at $16 \mathrm{~Hz}(R 16)$, in the basal state (continuous negative airway pressure $(\mathrm{CNAP})=0)$ and with CNAP levels of $-5,-10$, and $-15 \mathrm{hPa}$. Obstructive sleep apnoea syndrome $(\text { OSAS })_{1}$ patients $(\mathbb{Z})$ with body mass index $(\mathrm{BMI})<29$ $\mathrm{kg} \cdot \mathrm{m}^{-2} ; \mathrm{OSAS}_{2}$ patients (ख) with $\mathrm{BMI} \geqslant 29 \mathrm{~kg} \cdot \mathrm{m}^{-2}$; controls ( $\square$ ). Data are presented as mean士sEM. ${ }^{*}: \mathrm{p}<0.05$ versus controls; **. $\mathrm{p}<0.01$ versus controls; ${ }^{+}: \mathrm{p}<0.005$ versus controls.

and 0.001 , respectively). Ers and RF significantly increased as the CNAP level decreased $(\mathrm{p}<0.0001$ for both) (fig. 5), whereas no significant change was observed for Irs. The CNAP-induced increases in Ers and RF were significantly greater in patients than in controls $(\mathrm{p}<0.001$ and 0.0001 , respectively).

At each CNAP level, a highly significant linear relationship was found in all 36 subjects, between $E$ rs and $R 0$ on the one hand, and RF and $R 0$ on the other, $(\mathrm{p}<0.0001$ for both), and the corresponding correlation coefficients increased as the CNAP level decreased, from $r^{2}=0.48$ and 0.39 at $\mathrm{CNAP}_{0}$, respectively, to $\mathrm{r}^{2}=0.81$ and 0.80 at $\mathrm{CNAP}_{-15}$ (fig. 6).

ROC curves for $R 0, E r s$, and RF at $\mathrm{CNAP}_{-15}$ show how these parameters could discriminate between OSAS patients and control subjects (fig. 7). OSAS patients were detected optimally by the cut-off points of $6.6 \mathrm{hPa} \cdot \mathrm{L}^{-1} \cdot \mathrm{s}$ for $R 0$ with a $67 \%$ sensitivity and a $93 \%$ specificity, $66.7 \mathrm{hPa} \cdot \mathrm{L}^{-1}$ for $E$ rs with a $90 \%$ sensitivity and a $67 \%$ specificity, and $13.6 \mathrm{~Hz}$ for RF with an $81 \%$ sensitivity and a $93 \%$ specificity.

\section{Discussion}

To the authors' knowledge, this is the first study which compares the responses of respiratory impedance to decreasing CNAP levels in OSAS patients and
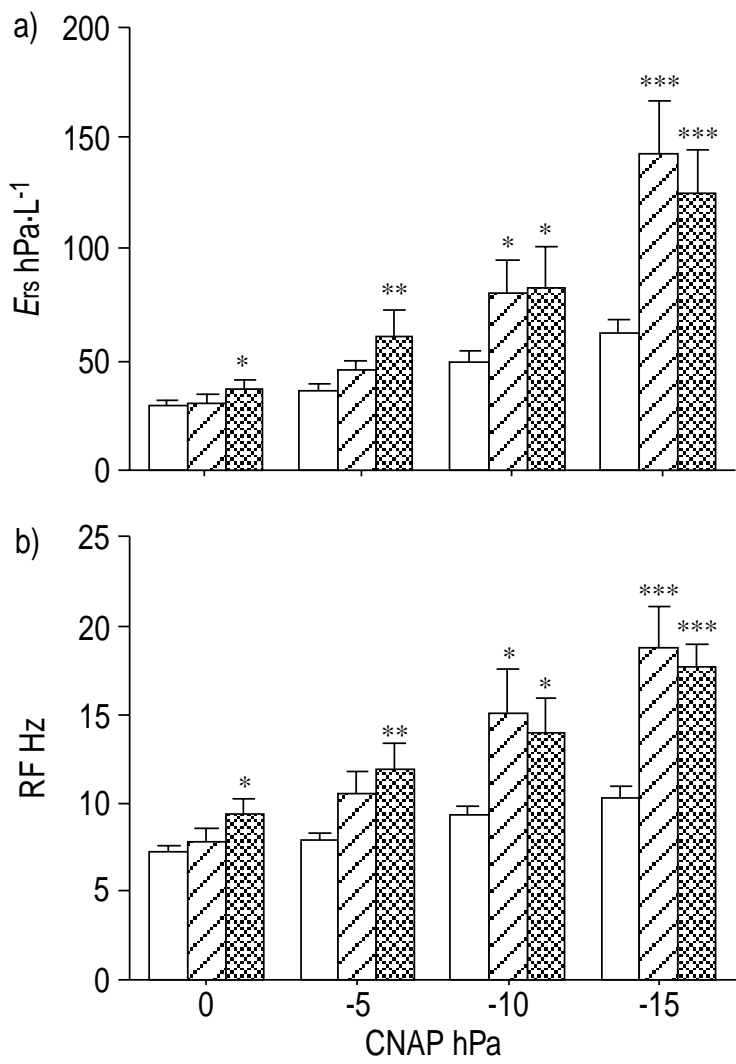

Fig. 2. - a) Respiratory elastance $\left(E_{\mathrm{rs}}\right)$ and b) resonance frequency $(\mathrm{RF})$ in the basal state (continuous negative airway pressure $(\mathrm{CNAP})=0)$ and with CNAP levels of $-5,-10$, and $-15 \mathrm{hPa}$. Obstructive sleep apnoea syndrome (OSAS), patients $(\mathbb{Z})$ with body mass index $(\mathrm{BMI})<29 \mathrm{~kg} \cdot \mathrm{m}^{-2} ; \mathrm{OSAS}_{2}$ patients (掣) with BMI $\geqslant 29 \mathrm{~kg} \cdot \mathrm{m}^{-2}$; controls $(\square)$. Data are presented as mean \pm SEM. *: $\mathrm{p}<0.05$ versus controls; **: $\mathrm{p}<0.01$ versus controls; $* * *: \mathrm{p}<$ 0.001 versus controls.

normal subjects, and which demonstrates that resonance frequency best allows discrimination between the two groups. The ages of controls and OSAS patients did not differ but the male: female ratio was lower in the controls than in the patients. However, it may be assumed that this difference did not influence the authors' results, since a previous study has shown that, despite the anatomical and functional differences of the UA in males and females, the $R$ rs responses to decreasing CNAP levels were similar in both sexes [12].

Initially, the authors divided the patients into two groups, in order to dissociate the respective influences of OSAS and BMI on the mechanical respiratory parameter values. That way, any difference between controls and $\mathrm{OSAS}_{1}$ could be attributed to the presence of OSAS, whereas any difference between $\mathrm{OSAS}_{1}$ and $\mathrm{OSAS}_{2}$ could be attributed to the severity of obesity.

It would have been more relevant to the clinical situation of OSAS if impedance measurements had been made in the supine position and via the nose. However, both the supine position and application of CNAP tend to promote nasal congestion, which would have resulted in unstable $R$ rs values. Furthermore, it may be assumed that the influence of nasal congestion on Rrs would have depended on the CNAP level and thereby biased the authors' results. In addition, neck position is more difficult to control when supine, and 

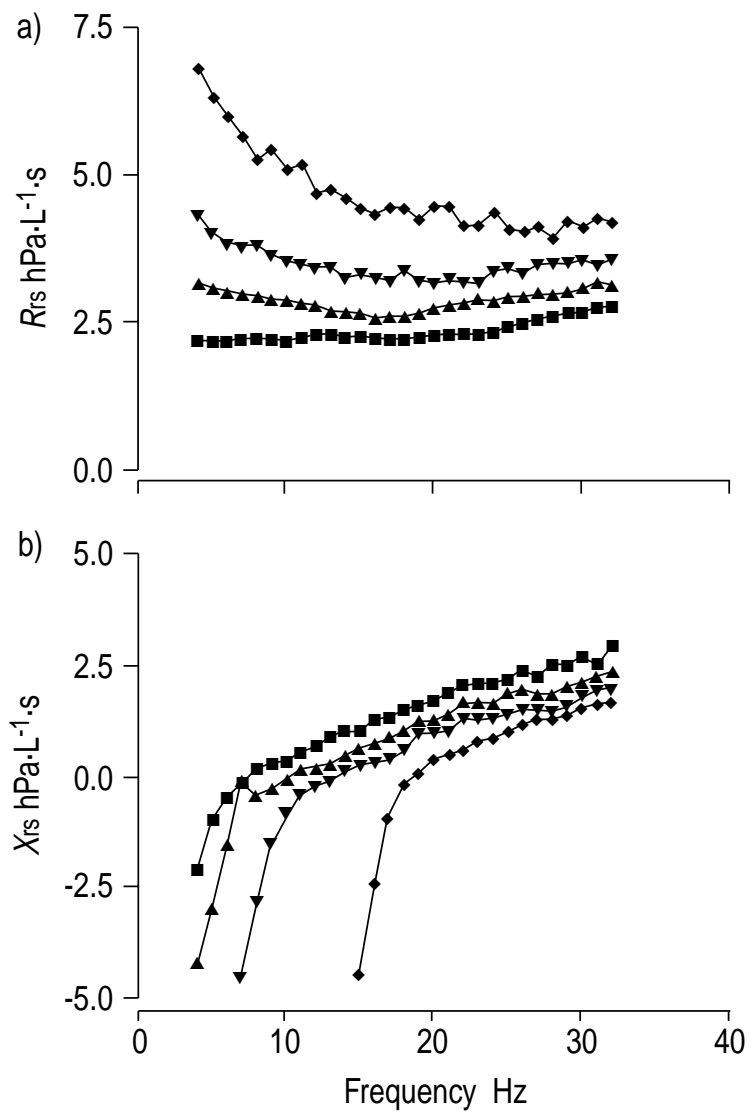

Fig. 3. - Typical frequency responses of a) respiratory resistive impedance $(R \mathrm{rs})$ and $\mathrm{b})$ reactance $(X \mathrm{rs})$ to decreasing continuous negative airway pressure (CNAP) levels of $0,-5,-10$ and -15 $\mathrm{hPa}$, in a representative obstructive sleep apnoea syndrome subject. $\square$ : CNAP $0 \mathrm{hPa} ; \boldsymbol{\Delta}$ : CNAP $-5 \mathrm{hPa} ; \boldsymbol{\nabla}$ : CNAP -10 hPa; $\checkmark$ : CNAP $-15 \mathrm{hPa}$.

neck extension or flexion is known to affect UA geometry [17], and consequently $R$ rs. Lastly, compared to the sitting position, the supine position induces an immediate decrease in end-expiratory lung volume (EELV), and consequently increases in Rrs, Ers Irs, and RF [18], which might have affected the responses of these parameters to decreasing CNAP levels.

The FOT was used, as opposed to the classical oesophageal balloon technique for assuming respiratory mechanics, because: 1) FOT is a noninvasive method, i.e. it does not necessitate the placement of a nasopharyngeal catheter which may influence UA resistance during CNAP application [19]; 2) FOT provides respiratory parameters, i.e. parameters which describe the mechanical behaviour of both the pulmonary component and the chest wall component, including respiratory muscles; and 3) with appropriate frequencies, FOT allows measurement of Newtonian respiratory resistance, and delayed respiratory resistance not including tissue viscoelasticity $[15,20]$, as well as respiratory reactance and its derived parameters. The authors, therefore, chose pseudorandom forced flow rather than a monosinusoidal oscillation, in order to study the frequency dependence of respiratory resistance, and to determine the parameters characterizing respiratory reactance, namely respiratory elastance,
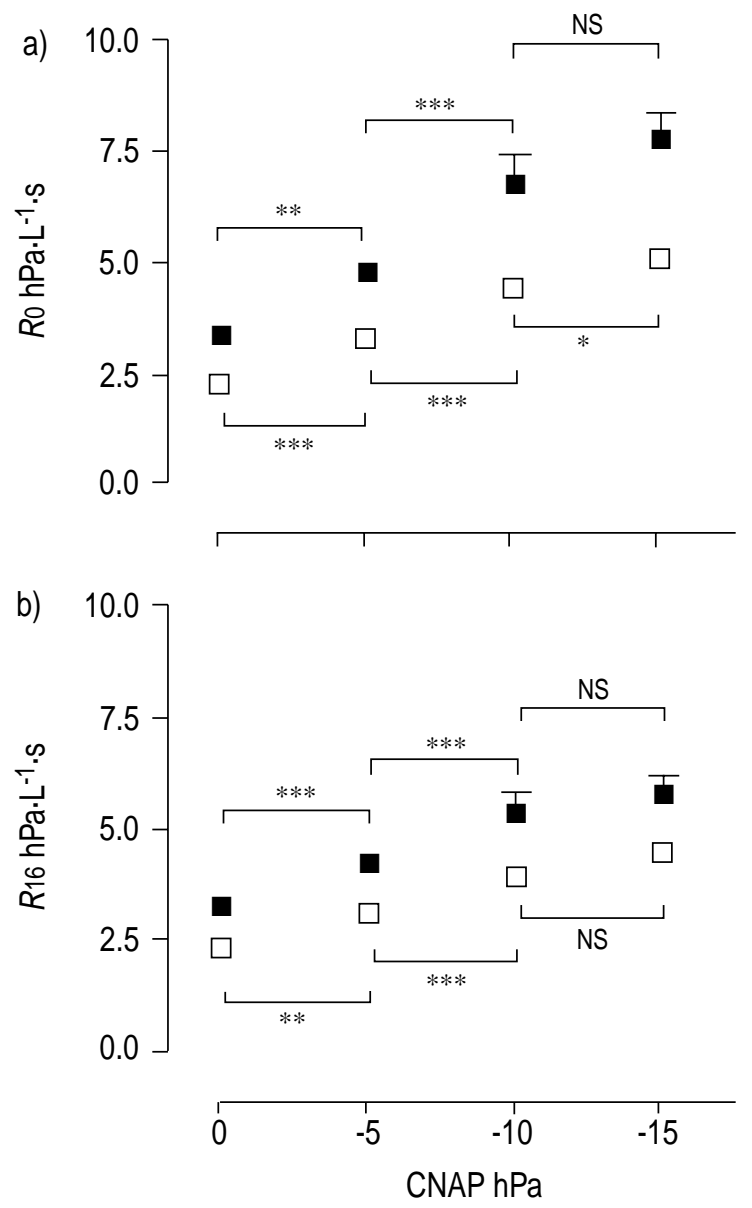

Fig. 4. - Respiratory resistive impedance a) extrapolated to $0 \mathrm{~Hz}$ $(R 0)$, and b) estimated at $16 \mathrm{~Hz}(R 16)$, in the basal state (continuous negative airway pressure $(\mathrm{CNAP})=0$ ), and with CNAP levels of $-5,-10$ and $-15 \mathrm{hPa}$, in obstructive sleep apnoea patients (ם) and controls $(\square)$. Data are presented as meantSEM. *: p $<$ 0.05 ; **: $\mathrm{p}<0.01 ; * * *: \mathrm{p}<0.001$; NS: nonsignificant difference.

inertance, and resonance frequency. However, the pseudorandom forced flow did not allow partitioning of airway resistance into inspiratory and expiratory resistances.

The authors chose two complementary indices of respiratory resistance, namely $R 0$ and $R 16$. Indeed, $R$ rs, which was roughly constant over $4-32 \mathrm{~Hz}$ in subjects with normal lungs, showed negative frequency dependence when gas redistribution within the airways occurred, as a result of series or parallel inhomogeneities [21]. As this frequency dependence occurs mainly below $16 \mathrm{~Hz}, R 16$ can be considered to reflect Newtonian respiratory resistance, and $R 0$, total respiratory resistance, i.e. Newtonian resistance plus the delayed airflow resistance resulting from gas redistribution, when present $[15,20]$. It also appeared interesting to consider the parameters derived from respiratory reactance. Indeed, parallel variations of $R 0$ and $\mathrm{RF}$ have been reported in the course of bronchial challenge tests to inhaled methacholine [22], and any increase in tissue elastance is associated with an increase in $E$ rs, and thereby in RF. 

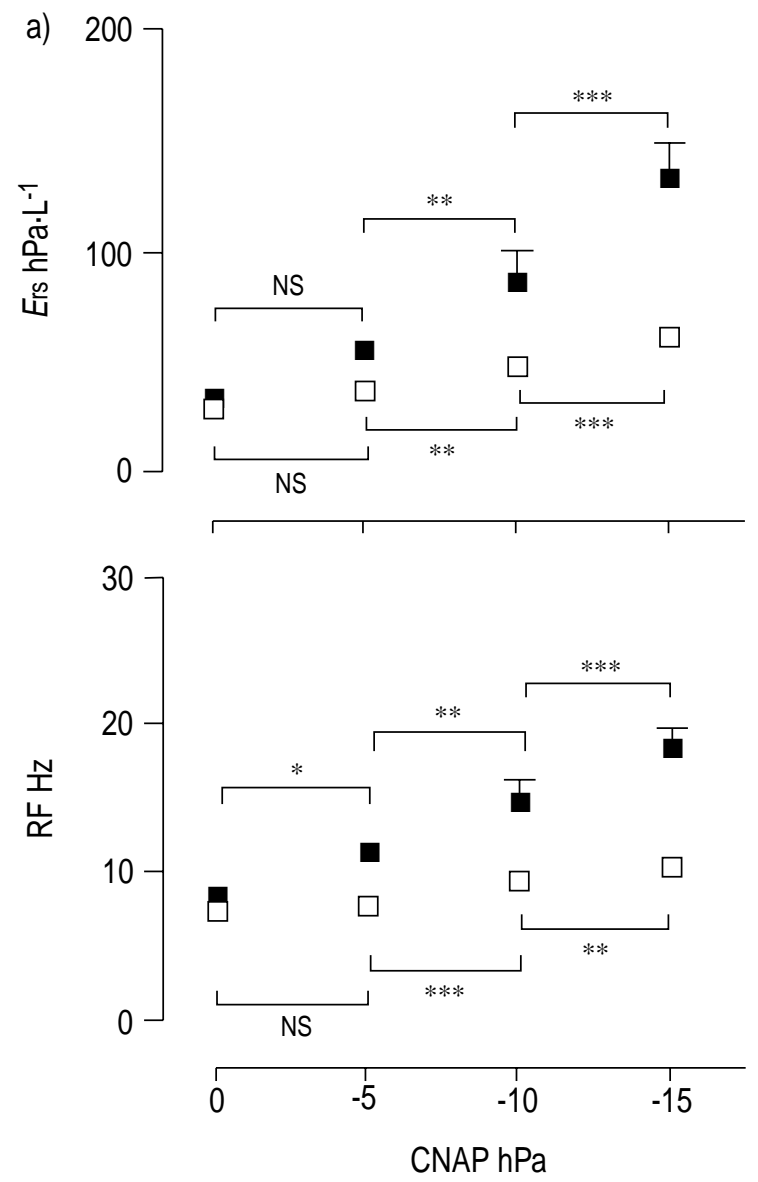

Fig. 5. - a) Respiratory elastance $\left(E_{\mathrm{rs}}\right)$ and b) resonance frequency (RF), in the basal state (continuous negative airway pressure $($ CNAP) $=0$ ) and with CNAP levels of $-5,-10$, and $-15 \mathrm{hPa}$, in obstructive sleep apnoea syndrome patients (ם) and controls

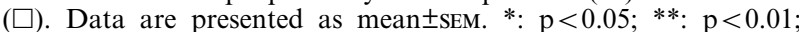
$* * *: \mathrm{p}<0.001$; NS: nonsignificant difference.

\section{Basal respiratory impedance}

The basal $R 0, E$ rs, and Irs values are in the range of those previously reported in normal subjects with or without minimal obesity $[18,23]$. The fact that basal $R 0$, and $R 16$ values were significantly higher in $\mathrm{OSAS}_{1}$ and $\mathrm{OSAS}_{2}$ groups than in controls, may be attributed to the OSAS factor. This result is in accordance with previous reports that for a comparable BMI, OSAS subjects have smaller pharyngeal cross-sectional areas [2] and higher $R$ rs values than non-OSAS subjects [5]. The fact that both basal $R 0$ and $R 16$ were not significantly different in $\mathrm{OSAS}_{1}$ and $\mathrm{OSAS}_{2}$ groups must be interpreted with caution, due to the small numbers in the groups. However, it suggests that airway geometry might be less influenced by the obesity factor than by the OSAS factor in subjects with normal lung volumes during wakefulness.

No significant difference was observed between basal $R 0$ and $R 16$ values in controls, $\mathrm{OSAS}_{1}$, and $\mathrm{OSAS}_{2}$, which illustrates the fact that $R$ rs was not frequency dependent. This result reflects homogeneous distribution of gas flow within the respiratory system [21], and
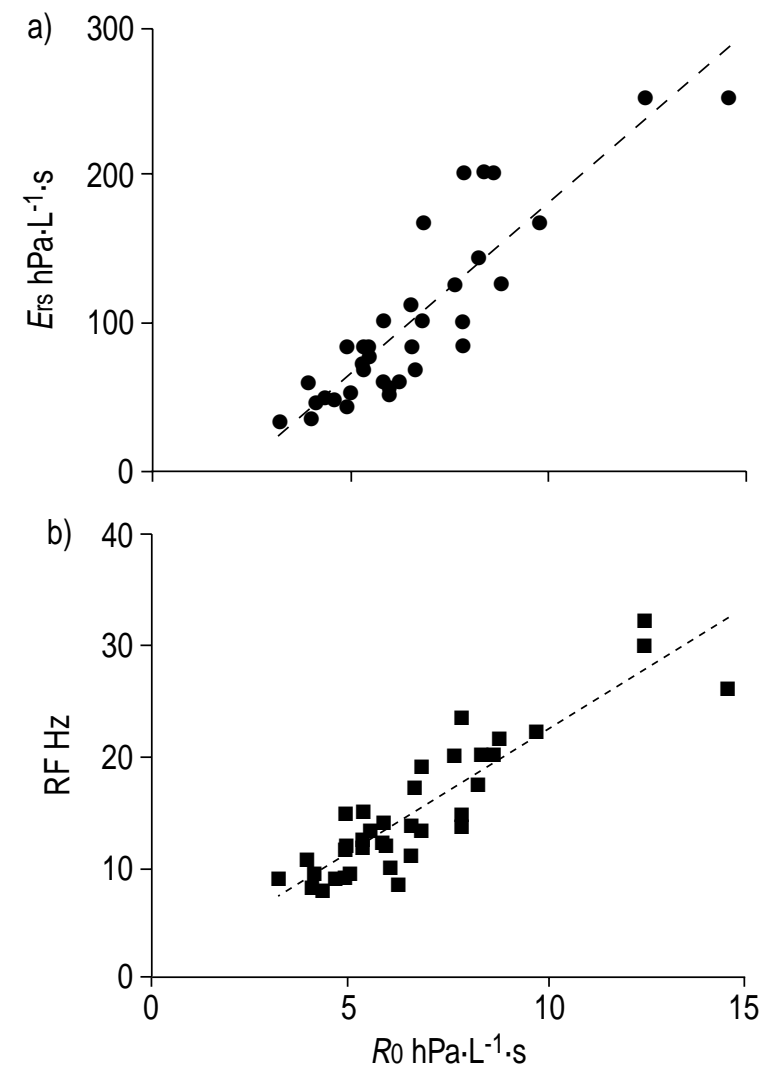

Fig. 6. - a) Respiratory elastance $(E \mathrm{rs})$ and b) resonance frequency (RF) at the continuous negative airway pressure level of $-15 \mathrm{hPa}$ (CNAP) plotted in relation to respiratory resistive impedance extrapolated to $0 \mathrm{~Hz}(R 0)$ at $\mathrm{CNAP}_{-15}$. Points represent data from individual subjects, and the straight lines are regression lines. a) $E \mathrm{rs}=23.2 R 0 \quad-51.3, \mathrm{r}^{2}=0.81, \mathrm{p}<0.0001$; b) $\mathrm{RF}=$ $2.18 R 0+0.43, \mathrm{r}^{2}=0.80, \mathrm{p}<0.0001$.

would be expected in subjects with no detectable airway obstruction.

Only the mechanical parameters derived from respiratory reactance, namely $E_{\mathrm{rs}}, I_{\mathrm{rs}}$, and RF, which were significantly different in $\mathrm{OSAS}_{1}$ and $\mathrm{OSAS}_{2}$, were influenced by obesity (fig. 2). These results are in accordance with those previously reported by ZERAH et al. [23] who attributed obesity-related increases in $E$ rs mainly to those in chest wall elastance.

Respiratory response to decreasing continuous negative airway pressure levels

The CNAP-induced increases in $R 0$ and $R 16$ presently observed in controls (figs. 1 and 4) are comparable to those previously reported in a similar study [12], in which it was demonstrated that a direct lung volume effect on airway resistance could not totally explain the increase in Rrs [12], and that other factors were probably involved. These may include: 1) a narrowing of extrathoracic airways directly resulting from the CNAP-induced decrease in UA transmural pressure, since, for a given transrespiratory pressure, supralaryngeal resistance increases more during CNAP than during continuous positive extrathoracic pressure [9]; and 2) an indirect effect of lung deflation, i.e. an 


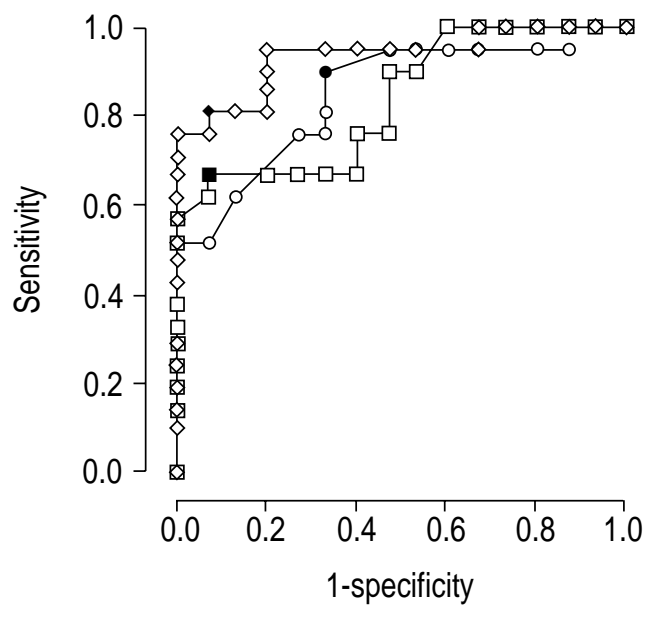

Fig. 7. - Receiver operator characteristic (ROC) curves for the respiratory parameters at the continuous negative airway pressure (CNAP) levels of $-15 \mathrm{hPa}$ to discriminate between obstructive sleep apnoea syndrome (OSAS) patients and normal subjects. $\square$ : respiratory resistive impedance extrapolated to $0 \mathrm{~Hz}$ $(R 0)$; $\bigcirc$ : respiratory elastance; and $\diamond$ : resonance frequency. The closed symbols represent optimal cut-off points.

additional increase in oropharyngeal resistance possibly due to an increase in UA collapsibility involving mechanical linkages between the thorax and the UA [24]. However, it is likely that the $R$ rs response to CNAP also resulted partly from an increase in tissue resistance $(R \mathrm{ti})$ due to the CNAP-induced decrease in lung volume [25].

The CNAP-induced increases in Ers reflect a decrease in respiratory compliance, i.e. in gas, and/or lung, and/ or chest wall compliance. Indeed, CNAP application induces significant decreases in EELV [12], and consequently in gas compliance. Furthermore, these decreases in EELV have already been reported to result in reduced lung compliance under CNAP, due to the sigmoid shape of the lung volume/transpulmonary pressure relationship [26]. Besides, decreases in respiratory reactance have previously been observed during resistive or elastic loading, and attributed to an increase in tissue elastance resulting from increased respiratory muscle activity [27]. As it has been reported that CNAP application results in an increase in diaphragmatic and parasternal intercostal electromyographic activity [10, 28], the Ers response to CNAP presently observed may be explained by the enhanced activity of inspiratory muscles. As Irs remained unchanged when the CNAP level was decreased, the significant increases observed in RF directly result from those in Ers.

The fact that $\Delta R \mathrm{rs}$ increased significantly as the CNAP level decreased, i.e. that $R$ rs became more and more frequency dependent, may be attributed to: 1) the increase in $R$ ti resulting from reduced lung volume, which has been reported to be more pronounced at the lower frequencies [25]; and 2) the occurrence and development of series and/or parallel gas redistribution [21]. Series gas redistribution is mainly due to UA shunt compliance, whose influence on Rrs was probably reduced under CNAP, due to the increased activity of UA dilating muscles [10]. Consequently, it is more probable that parallel gas redistribution developed within intrathoracic airways, as a result of the pulmonary inhomogeneities promoted by the CNAPinduced decrease in lung volume.

An interesting result is that none of the responses of the respiratory mechanical parameters to decreasing CNAP levels were significantly different in groups $\mathrm{OSAS}_{1}$ and OSAS 2 . This suggests that, whereas in the basal state, Ers, Irs, and RF were slightly influenced by the obesity level in subjects with normal lung volumes, at low CNAP levels they depend mainly on the physiological conditions of the ventilation, namely decreased lung volume and increased respiratory muscle activity. Consequently, any difference between the respiratory responses to CNAPs in control and OSAS subjects can be considered independent of the obesity level.

The improvement in the quality of the linear relationship between $E$ rs and $R 0$ when decreasing the CNAP level may be explained as follows: $R 0$ represents the resistance to be overcome by the respiratory muscles, to the exclusion of the delayed resistance due to the tissue viscoelastic properties [15]; Ers partly reflects respiratory muscle activity; both $R 0$ and Ers increase as the CNAP level is lowered. As Irs remained unchanged, the improvement in the quality of the linear relationship between RF and $R 0$ when decreasing the CNAP level may be similarly explained.

\section{Comparisons between control and obstructive sleep apnoea syndrome subjects}

Surprisingly, no significant difference was observed between the two groups regarding the response of $R 16$ to decreasing CNAP levels. An enhanced response of UA resistance to negative transmural pressures might be expected in OSAS patients whose UAs are narrower and more collapsible [4, 8]. Therefore, it could be speculated that UA patency was maintained at the cost of a greater increase in UA muscle electromyographic activity in OSAS than in normal subjects, as previously observed in patients during sleep [29]. The CNAPinduced increase in UA muscle activity appears to result from the simultaneous occurrences of the decrease in lung volume, the low intraluminal pressure, and the increase in diaphragmatic activity, since it has been reported that: 1) the active reduction of EELV results in increased UA muscle activity [30]; 2) when the CNAP-induced decrease in EELV is prevented by applying identical pressure to the body surface, UA muscle activity is enhanced, despite the absence of change in diaphragmatic activity [11]; and 3) UA muscle activity responds to CNAP in a manner similar to diaphragmatic activity [10]. The difference between the increases in Ers observed in the two groups strongly suggests that the CNAP-induced increase in diaphragmatic activity was greater in OSAS than in control subjects. In this connection, it has been reported that the activation of UA dilators is reflected by indices that quantify the central inspiratory drive, and that for the same increase in the central inspiratory drive, the decrease in pharyngeal resistance is more marked in OSAS patients than in normal subjects [31]. It is worth 
noting that, during inspiration, the compensatory increase in activity of the airway dilator muscles minimizes the suction effect of CNAP on extrathoracic airways. Consequently, the CNAP-induced increase in UA resistance was probably less than during expiration. The resistance values were, however , determined over the entire ventilatory cycle, and did not allow partitioning of airway resistance into inspiratory and expiratory resistances. Although no significant difference was observed between OSAS patients and control subjects regarding the responses of $R 16$ to decreasing CNAP levels, may it be speculated that the respective contributions of inspiratory and expiratory resistances to $R 16$ might have been different in OSAS and normal subjects.

The fact that the CNAP-induced increases in $R 0$ and $\Delta R$ rs were significantly greater in OSAS than in controls, might be due to a greater increase in $R$ ti and/or delayed airflow resistance resulting from intrapulmonary gas redistribution at low lung volume. OSAS may be an independent risk factor for small airway disease as assessed by abnormally low expiratory flow rates at 50 and $25 \%$ of the vital capacity [5]. Subclinical abnormalities of distal airways might thus be revealed with application of CNAP in OSAS subjects with normal lung function. Besides, the fact that the decreases in EELV were more marked in the patients than in the controls, cannot be excluded.

When comparing patients to controls, the CNAPinduced increases in Ers and RF were significantly more marked than those in $R 0$, probably because $R 0$ does not take into account the resistive component due to the tissue viscoelastic properties [15]. This component, which varies with lung volume [32], is partly responsible for the respiratory effort that $E \mathrm{rs}$, and consequently RF, may be assumed to reflect.

When comparing the ROC curves for $R 0, E \mathrm{rs}$, and $\mathrm{RF}_{\text {at }} \mathrm{CNAP}_{-15}$, to discriminate between control and OSAS patients (fig. 7), it may be observed that the best results were obtained for RF which, for a given specificity, identified OSAS patients with the highest sensitivity. This shows that although highly correlated (fig. 6), the different indices derived from respiratory resistance and reactance do not provide redundant information.

In conclusion, this study demonstrated that the responses of respiratory impedance to decreasing continuous negative airway pressure levels differ in obstructive sleep apnoea syndrome and control subjects during wakefulness, and that this difference cannot be attributed to the obesity level. The results suggest that the response of respiratory impedance to decreasing continuous negative airway pressure, and more particularly the response of resonance frequency, which probably reflects the increase in respiratory muscle activity, might allow discrimination between control and obstructive sleep apnoea syndrome subjects with normal lung function. Thus, the application of subatmospheric pressures might be useful as a screening test for obstructive sleep apnoea syndrome during wakefulness, although additional studies including a larger number of subjects are needed before it can be recommended for this purpose.

\section{References}

1. Deegan PC, McNicholas WT. Pathophysiology of obstructive sleep apnoea. Eur Respir J 1998; 10: 29-62.

2. Bradley TD, Brown IG, Grossman RF, et al. Pharyngeal size in snorers, nonsnorers, and patients with obstructive sleep apnoea. N Engl J Med 1986; 315: 1327-1331.

3. Anch AM, Remmers JE, Bunce III H. Supraglottic airway resistance in normal subjects and patients with occlusive sleep apnoea. J Appl Physiol 1982; 53: 11581163.

4. Suratt PM, McTier RF, Wilhoit SC. Collapsibility of the nasopharyngeal airway in obstructive sleep apnea. Am Rev Respir Dis 1985; 132: 967-971.

5. Zerah-Lancner F, Lofaso F, Coste A, Ricolfi F, Goldenberg F, Harf A. Pulmonary function in obese snorers with or without sleep apnea syndrome. Am J Crit Care Med 1997; 156: 522-527.

6. Brown IG, Bradley TD, Phillipson EA, Zamel N, Hoffstein V. Pharyngeal compliance in snoring subjects with and without obstructive sleep apnea. Am Rev Respir Dis 1985; 132: 211-215.

7. Brown IG, McClean PA, Boucher R, Zamel N, Hoffstein V. Changes in pharyngeal cross-sectional area with posture and application of continuous positive airway pressure in patients with obstructive sleep apnea. Am Rev Respir Dis 1987; 136: 628632.

8. Suratt PM, Wilhoit SC, Cooper K. Induction or airway collapse with subatmospheric pressure in awake patients with sleep apnea. $J$ Appl Physiol 1984; 57: 140-146.

9. Sériès F, Marc I. Influence of lung volume dependence of upper airway resistance during continuous negative airway pressure. J Appl Physiol 1994; 77: 840-844.

10. Aronson RM, Önal E, Carley DW, Lopata M. Upper airway and respiratory muscle responses to continuous negative airway pressure. J Appl Physiol 1989; 66: 1373-1382.

11. Leiter JC, Daubenspeck JA. Selective reflex activation of the genioglossus in humans. J Appl Physiol 1990; 68: 2581-2587.

12. Lorino AM, Hamoudi K, Lofaso F, et al. Effects of continuous negative airway pressure on lung volume and respiratory resistance. J Appl Physiol 1999; 87: 605-610.

13. Peslin R, Felicio da Silva J, Duvivier C, Chabot F. Respiratory mechanics studied by forced oscillations during mechanical ventilation. Eur Respir J 1993; 6: $772-784$.

14. Lorino H, Mariette C, Karouia M, Lorino AM. Influence of signal processing on estimation of respiratory impedance. J Appl Physiol 1993; 74: 215223.

15. Lorino AM, Zerah F, Mariette C, Harf A, Lorino H. Respiratory resistive impedance in obstructive patients: linear regression analysis versus viscoelastic modelling. Eur Respir J 1997; 10: 150-155.

16. Altman DG. Practical statistics for Medical Research. London, Chapman and Hall, 1991; pp. 417-418.

17. Liistro G, Stanescu D, Dooms G, Rodenstein R, Veriter C. Head position modifies upper airway resistance in men. J Appl Physiol 1988; 64: 1285-1288.

18. Lorino AM, Atlan G, Lorino H, Zanditenas D, Harf A. Influence of posture on mechanical parameters 
derived from respiratory impedance. Eur Respir $J$ 1992; 5: 1118-1122.

19. Nahmias JS, Karetzy MS. Treatment of the obstructive sleep apnea syndrome using a nasopharyngeal tube. Chest 1998; 94: 1142-1147.

20. Beydon L, Malassiné P, Lorino AM, et al. Respiratory resistive impedance by end-inspiration occlusion and forced oscillations in intubated patients. J Appl Physiol 1996; 80: 1105-1111.

21. Peslin R, Fredberg JJ. Oscillation mechanics of the respiratory system. In: Handbook of Physiology. The respiratory system. Bethesda, American Physiological Society, 1986; pp. 145-177.

22. Pairon JC, Iwatsubo Y, Hubert C, et al. Measurement of bronchial responsiveness by forced oscillation technique in occupational epidemiology. Eur Respir $J$ 1994; 7: 484-489.

23. Zerah F, Harf A, Perlemuter L, Lorino H, Lorino AM, Atian G. Effects of obesity on respiratory resistance. Chest 1993; 103: 1470-1476.

24. Van de Graaff WB. Thoracic influence on upper airway patency. J Appl Physiol 1988; 65: 2124-2131.

25. Peslin R, Duvivier C. Partitioning of airway and respiratory tissue mechanical impedances by body plethysmography. J Appl Physiol 1998; 84: 553-561.

26. Barnas GM, Sprung J, Craft TM, et al. Effect of lung volume on lung resistance and elastance in awake subjects measured during sinusoidal forcing. Anesthesiol 1993; 78: 1082-1090.

27. Peslin R, Tomalak W, Duvivier C. Influence of external loading and assisted ventilation on chest wall mechanical properties. Respir Physiol 1997; 108: 153-164.

28. Meessen NE, Van de Grinten CP, Luijendijk SC, Folgering HT. Continuous negative airway pressure increases tonic activity in diaphragm and intercostal muscles in humans. J Appl Physiol 1994; 77: 12561262.

29. Suratt PM, Mctier RF, Wilhoit SC. Upper airway muscle activation is augmented in patients with obstructive sleep apnea compared with that in normals. Am Rev Respir Dis 1988; 137: 889-894.

30. Aronson RM, Carley DW, Önal E, Wilborn J, Lopata M. Upper airway muscle activity and the thoracic volume dependence of upper airway resistance. $J \mathrm{Appl}$ Physiol 1991; 70: 430-438.

31. Sériès F, Cormier Y, Desmeules M, La Forge J. Effects of respiratory drive on upper airways in sleep apnea patients and normal subjects. J Appl Physiol 1989; 67: 973-979.

32. D'Angelo E, Calderini E, Torri G, Robatto FM, Bono D, Milic-Emili J. Respiratory mechanics in anesthetized paralyzed humans: effects of flow, volume, and time. J Appl Physiol 1989; 67: 2556-2564. 